\title{
Self-Organized Nanostructure Modified Microelectrode for Sensitive Electrochemical Glutamate Detection in Stem Cells-Derived Brain Organoids
}

\author{
Babak Nasr ${ }^{1,2,3, *(1)}$, Rachael Chatterton ${ }^{1}$, Jason Hsien Ming Yong ${ }^{1,2}$, Pegah Jamshidi ${ }^{1}$, \\ Giovanna Marisa D'Abaco ${ }^{4}$, Andrew Robin Bjorksten ${ }^{5}$, Omid Kavehei ${ }^{6}$ (i), \\ Gursharan Chana ${ }^{1,7}$, Mirella Dottori ${ }^{1,2,8, *}$ and Efstratios Skafidas ${ }^{1,2,3}$ \\ 1 Centre for Neural Engineering, The University of Melbourne, Melbourne, VIC 3053, Australia; \\ rachael.chatterton@florey.edu.au (R.C.); jasony1@student.unimelb.edu.au (J.H.M.Y.); \\ golpeg@yahoo.com (P.J.); gchana@unimelb.edu.au (G.C.); sskaf@unimelb.edu.au (E.S.) \\ 2 The Department of Electrical and Electronic Engineering, The University of Melbourne, Melbourne, \\ VIC 3010, Australia \\ 3 ARC Centre of Excellence for Integrative Brain Function, The University of Melbourne, Melbourne, \\ VIC 3010, Australia \\ 4 The Department of Biomedical Engineering, The University of Melbourne, Melbourne, VIC 3010, \\ Australia; gdabaco@unimelb.edu.au \\ 5 The Department of Anaesthesia \& Pain Management, Royal Melbourne Hospital, Parkville, VIC 3050, \\ Australia; andrew.bjorksten@mh.org.au \\ 6 Faculty of Engineering and Information Technology, The University of Sydney, Sydney, NSW 2006, \\ Australia; omid.kavehei@sydney.edu.au \\ 7 Department of Medicine, Royal Melbourne Hospital, The University of Melbourne, Melbourne, VIC 3050, \\ Australia \\ 8 Illawarra Health and Medical Research Institute, Centre for Molecular and Medical Bioscience, \\ University of Wollongong, Wollongong, NSW 2522, Australia \\ * Correspondence: babak.nasr@unimelb.edu.au (B.N.); mdottori@uow.edu.au (M.D.); Tel.: +61-3-903-54407 (B.N.); \\ +61-2-4221-5233 (M.D.)
}

Received: 10 January 2018; Accepted: 31 January 2018; Published: 5 February 2018

\begin{abstract}
Neurons release neurotransmitters such as glutamate to communicate with each other and to coordinate brain functioning. As increased glutamate release is indicative of neuronal maturation and activity, a system that can measure glutamate levels over time within the same tissue and/or culture system is highly advantageous for neurodevelopmental investigation. To address such challenges, we develop for the first time a convenient method to realize functionalized borosilicate glass capillaries with nanostructured texture as an electrochemical biosensor to detect glutamate release from cerebral organoids generated from human embryonic stem cells (hESC) that mimic various brain regions. The biosensor shows a clear catalytic activity toward the oxidation of glutamate with a sensitivity of $93 \pm 9.5 \mathrm{nA} \cdot \mu \mathrm{M}^{-1} \cdot \mathrm{cm}^{-2}$. It was found that the enzyme-modified microelectrodes can detect glutamate in a wide linear range from $5 \mu \mathrm{M}$ to $0.5 \mathrm{mM}$ with a limit of detection (LOD) down to $5.6 \pm 0.2 \mu \mathrm{M}$. Measurements were performed within the organoids at different time points and consistent results were obtained. This data demonstrates the reliability of the biosensor as well as its usefulness in measuring glutamate levels across time within the same culture system.
\end{abstract}

Keywords: microelectrodes; electrochemical biosensors; amperometry; glutamate; human embryonic stem cells; organoids 


\section{Introduction}

Glutamate is the principal excitatory neurotransmitter in the brain. In addition to its neuronal signaling role, glutamate also plays critical roles in cortical development, including migration and differentiation of cortical neurons. In contrast, high levels of glutamate may cause excitotoxicity and neuronal death that are associated with multiple neuronal diseases, such as ischemia [1,2], Parkinson's disease [3,4], Alzheimer's disease [5,6], and epilepsy [7-9].

These important roles of glutamate have generated a strong interest in the development of devices for the detection and monitoring of this amino acid. Moreover, given its fundamental role in corticogenesis and brain functioning, it would be valuable to measure glutamate levels at different stages of human brain development and within brain regions, with relevance to neurodevelopmental disorders. Neurospheres and cerebral organoids derived from human pluripotent stem cells (hPSC) consist of a heterogeneous mix of differentiating neural and glia cell types and can therefore mimic many of the dynamic processes occurring during brain development. This includes proliferation of neuroepithelial cells, neural/glial differentiation and cortical patterning. Using small molecule agonists and growth factors, neuronal cell fate within hPSC-derived neurospheres/organoids may also be biased to model different brain regions. hPSC-derived organoids can also be generated from patients suffering from neurodevelopmental or neurodegenerative conditions as potential disease models. Therefore, the development of a system that allows multiple and continuous measurements of glutamate levels within the same hPSC organoids cultured over time would greatly facilitate growing organoids with regional and disease specific characteristics.

Different methods have been established to determine glutamate levels, including optical methods [10,11], patch clamp [12], and microdialysis [13], as well as fluorometric [14], chromatographic [15], or spectrophotometric techniques [16,17]. Many of these techniques have intrinsic limitations, such as being time-consuming, requiring pre-treatment of the sample, being labour intensive, and requiring skilled handling. In contrast, electrochemical methods are considered as one of the most promising approaches because of low cost, simplicity, high sensitivity and specificity, which is ideal for point-of care, implantable and portable devices [18-20]. Amongst neurochemical devices, a range of amperometric biosensors have been developed based on loaded glutamate oxidase enzyme [21-23].

Here, we report the development and characterization of an enzyme based "micropipette-like" electrode with nanotextured probe, which is suitable for application in measuring glutamate levels within human embryonic stem cells (hESCs) derived organoids. We chose to test our microelectrode in a 3D organoid model in recognition of two-dimensional cell culture systems not being able to recapitulate the complexity of brain architecture and functioning. By creating nanostructures on the probe surface area we increased the binding capacity for the functional molecules to contribute in reactions at the surface, thus facilitating the acquisition and transportation of signals and improving sensitivity [24-28]. The performance of our nanotextured electrode was examined in hESC-derived organoids consisting of different neuronal populations that are representative of different brain regions and therefore likely differ in their glutamate levels. Measurements of glutamate levels were performed within the same organoids and across different timepoints in culture, thereby showing the multi-use application of the biosensor in live cell cultures. Overall, these studies demonstrate a novel approach for measuring dynamic changes of neurrotransmitter levels within hESC-derived cerebral organoids, a necessity for developing improved neurodevelopmental and neurological disorder models.

\section{Materials and Methods}

\subsection{Materials}

Dopamine (DA), ascorbic acid (AA), cysteine (Cus), uric acid (UA), serotonin, glucose, dihydroxyphenylacetic acid (DOPAC), alanine (Ala); arginine (Arg); asparagine (Asn); aspartic acid (Asp); glycine (Gly); histidine (His); trans-4-hydroxyl-L-proline (Hyp); isoleucine (Ile); leucine 
(Leu); lysine (Lys) and phosphate-buffered saline solution (PBS) all purchased from Sigma-Aldrich. Alexa Fluor ${ }^{\circledR} 488$ anti-rabbit-IgG antibody, DMEM/F12 medium, rabbit anti-v-Glut antibody (Abcam, Melbourne, Australia), mouse anti-GAD67 (EMD Millipore, Bayswater, Australia) and goat anti-rabbit (555 nm) purchased from Molecular probes, Life Technology.

\subsection{Apparatus}

Self-organized nanostructures were formed by means of reactive ion etching (Oxford Plasma Lab100, Oxford instruments, Abingdon, UK). Metallization was performed via electron beam evaporation (Intlvac Nanochrome, Fort Collins, CO, USA). The glass micro-needles were prepared through a flaming micropipette puller (P-100 Sutter Instrument, Novato, CA, USA). The amperometric experiments were computer controlled with data acquisition that was realized using a CHI760 interface, a low-noise damping potentiostat (600 E, CH Instruments, Austin, TX, USA). Surface analysis of fabricated microelectrodes was carried out using scanning helium ion microscopy (Nanofab Orion, Zeiss, Peabody, MA, USA). Fluorescence images were captured using a confocal microscope (Leica SP8, Wetzlar, Germany) with Leica Application Suite X software.

\subsection{Biosensor Design and Fabrication}

Figure 1 shows a schematic illustration of the biosensor fabrication process. The glass micro-needles were prepared by pulling borosilicate glass capillaries (i.d. $1.16 \mathrm{~mm}, 75 \mathrm{~mm}$ long, SDR scientific) through a flaming micropipette puller as shown in Figure 1a. The micropipettes with suitable geometry (smoothly tapered with tip size of $10 \mu \mathrm{m}$ ) were fabricated by adjusting the pulling program. The glass surfaces were cleaned with acetone, 2-propanol, deionized water and loaded into a reactive ion etcher (RIE) chamber to develop self-organized nanostructures under pseudo Bosch process [29]. The RIE was carried out for $20 \mathrm{~min}$ at RF/ICP powers of $600 \mathrm{~W} / 30 \mathrm{~W}$ and etching gas $\left(\mathrm{SF}_{6}: 100 \mathrm{sccm}\right.$ and $\mathrm{O}_{2}$ : $10 \mathrm{sccm}$ ) while the chamber pressure stabilized at 20 torr.
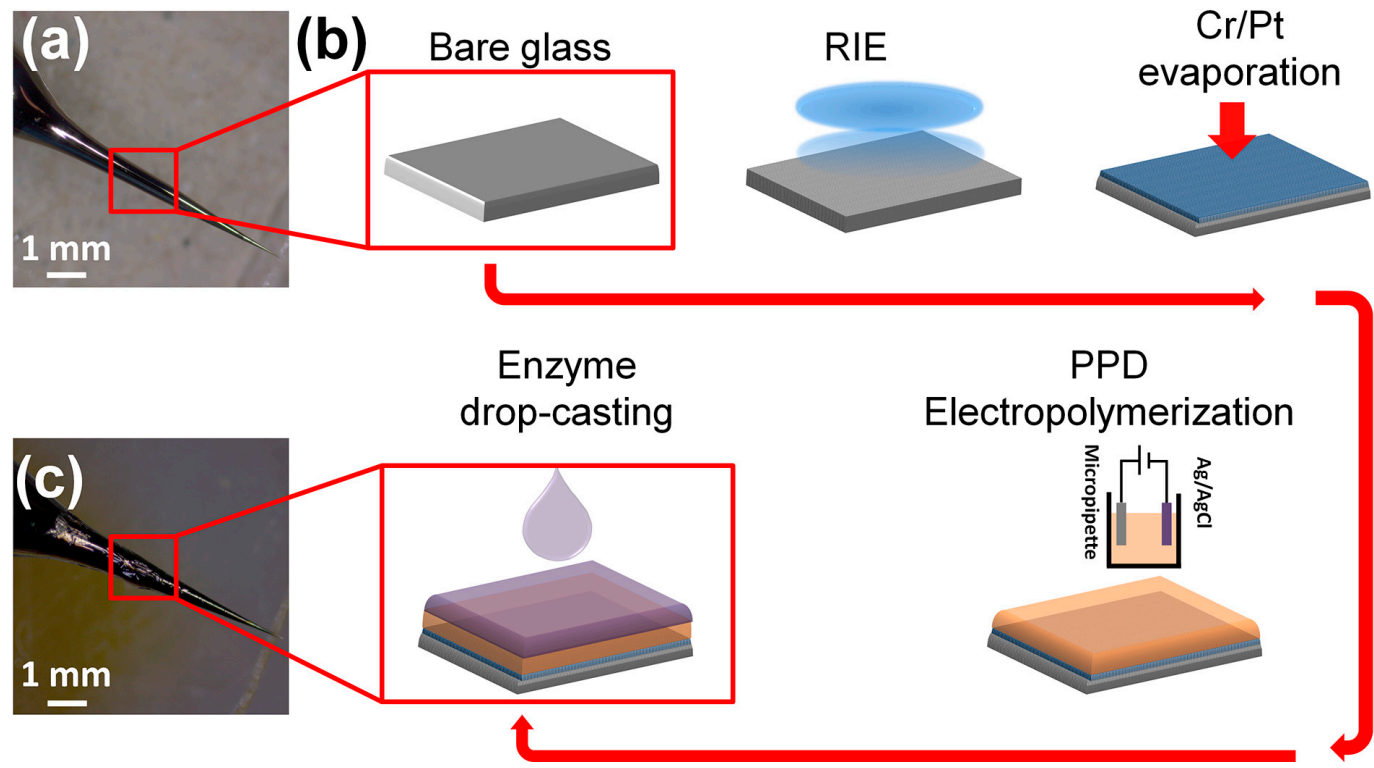

Figure 1. Biofabrication: (a) Top left: An optical image of a bare micropipette, used as the platform for microelectrode fabrication and glutamate biosensing. (b) Schematic illustration of microelectrode preparation. The microelectrode underwent RIE processing to increase the effective surface area by forming a nanostructured texture, followed by $\mathrm{Cr}$ and $\mathrm{Pt}$ deposition to form a signal transducer. The microelectrode was then modified by an electropolymerized PPD and covered by enzymatic film. (c) bottom left: An optical image of the final microelectrode covered by GluOx layer ready for amperometric measurements. 
A helium ion microscope (HIM) equipped with charge cancellation system was used to observe and inspect the probe surface area of the microelectrode. The HIM was armed with a very low voltage electron gun (flood gun) to compensate for positive surface charge accumulation on the bare glass surface. During imaging the electron beam energy and the $X$ and $Y$ deflectors were adjusted correspondingly to ensure the best possible image. Figure 2a shows the HIM viewgraph of the probe and high-resolution image of nanostructured surface morphology (Figure 2b). A conductive thin film of $\mathrm{Cr} / \mathrm{Pt}$ (30 nm/70 nm) was deposited on micropipettes by e-beam evaporation to act as the electrochemical transducer (Figure $2 \mathrm{c}, \mathrm{d}$ ). The micropipettes were vertically mounted on a rotation stage in deposition chamber and positioned above the vapor source to achieve uniform metallic coating at the tip of electrodes. The rotation speed of $20 \mathrm{rpm}$ was maintained throughout the evaporation process.

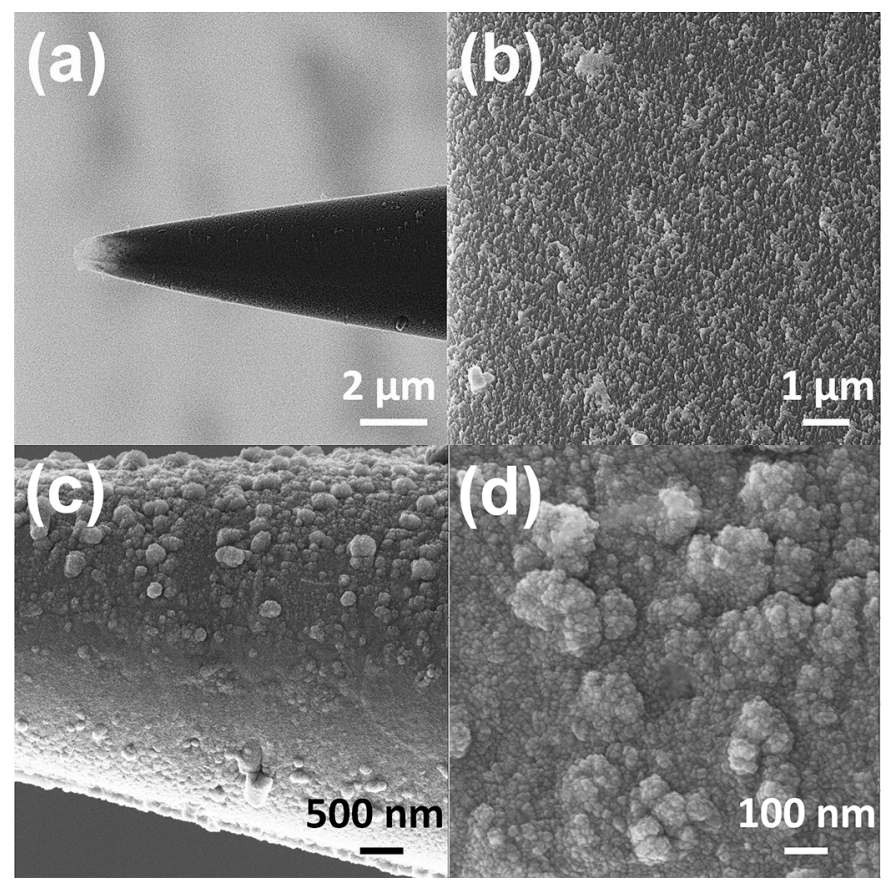

Figure 2. HIM imaging of a microelectrode (a) Overall view of the tip of a microelectrode used as probe for glutamate detection in hESC. (b) High resolution image of self-organized nanostructures on the surface of the probe. (c) The structural rearrangement of the probe after $\mathrm{Cr} / \mathrm{Pt}$ deposition (d) High resolution image of the morphology of $\mathrm{Pt}$ coated nanostructures on the probe.

Copper wires were then bonded to the end of platinum microelectrodes using conductive silver paste. Next, a layer of epoxy resin was coated onto the Pt micropipettes while leaving a millimeter of the tip exposed for enzyme coating.

\subsection{Enzyme Immobilization on Microelectrodes}

A surface treatment method was developed to immobilize glutamate oxidase onto the surface of the microelectrode tip/probe. First poly(m-phenylenediamine), PPD, was electropolymerized onto the tip of the microelectrode using an amperometric process. The electropolymerization is the most common technique for applying polymer films as it allows easy control of thickness of polymeric layer and a homogeneous coating onto electrodes with complex geometry [30]. A solution of PPD (100 mmol/L) was made up in $10 \mathrm{~mL}$ of a $0.01 \mathrm{M}$ phosphate-buffered saline solution (PBS) with dissolution achieved by sonication at $25{ }^{\circ} \mathrm{C}$ for $25 \mathrm{~min}$. The electro-oxidative polymerization was then performed by holding the potential at $0.7 \mathrm{~V}$ with reference to $\mathrm{Ag} / \mathrm{AgCl}$ for $20 \mathrm{~min}$ followed by immobilization of glutamate oxidase (GluOx) via drop casting. The enzymatic solution consisted of $5 \mu \mathrm{L}$ of phosphate buffered saline solution (PBS $0.01 \mathrm{M}$, pH 7.4) containing 10\% BSA and 0.125\% 
glutaraldehyde, which was mixed with $5 \mu \mathrm{L} \mathrm{GluOx}(50 \mathrm{U} / \mathrm{mL})$. The exposed surface area was then drop coated repetitively (10 times with one-minute interval) with microdrops $(\sim 1 \mu \mathrm{L})$ of enzyme mixture using Eppendorf micropipette while the microelectrode turned over every time before drop casting to ensure a uniform coating. (Figure 1c). After the coating procedure, sensors were cured at least $24 \mathrm{~h}$ at $4{ }^{\circ} \mathrm{C}$ prior to use. A very thin yellow transparent layer could be seen under a microscope.

\subsection{Cell Culture}

This project was approved by the University of Melbourne Human Ethics Committee (\#1545384). The hESC (WA-09, WiCell, Madison, SD, USA) cell line was cultured feeder free on vitronectin-coated plates using MTeSR-1 defined media according to the manufacturer's instructions (Stem Cell Technologies, Tullamarine, Australia) and maintained at $37{ }^{\circ} \mathrm{C}$ and $5 \% \mathrm{CO}_{2}$. Colonies were mechanically dissected every 7 days and transferred to freshly coated plates. Cell culture medium was changed every day. Neural induction and organoid formation of hESC were set up as described by Denham and Dottori, with some minor modifications [31]. HESC colonies were mechanically dissected into pieces approximately $0.5 \mathrm{~mm}$ in width and transferred to laminin-coated organ culture plates in 'N2B27' medium containing 1:1 mix of DMEM/F12 medium and neural basal media (Life Technologies/Invitrogen, Carlsbad, NM, USA) supplemented with $1 \%$ insulin/transferrin/selenium (Life Technologies/Invitrogen), $1 \% \mathrm{~N}_{2}$ supplement (Life Technologies/Invitrogen), $1 \%$ retinol-free B27 supplement (Life Technologies/Invitrogen), 0.3\% glucose, $25 \mathrm{U} / \mathrm{mL}$ penicillin, and $25 \mu \mathrm{g} / \mathrm{mL}$ streptomycin (Life Technologies/Invitrogen). For differentiation to dorsal forebrain neurons, N2B27 defined medium was supplemented with the small molecules SB431542 (10 uM, Tocris, Bristol, UK) and LDN193189 (100 nM, KareBay Biochem, Monmouth Junction, NJ, USA) for 7 days. For differentiation to ventral forebrain neurons, N2B27 was supplemented with small molecules SB431542 $(10 \mu \mathrm{M})$, LDN193189 (100 nM), and Smoothen Agonist (SAG; 400 nM, Merck Millipore, Bayswater, Australia) for 7 days. Following initial neural induction, colonies from dorsal or ventral forebrain neural inductions were treated with N2B27 medium supplemented with basic-fibroblast growth factor (bFGF; $20 \mathrm{ng} / \mathrm{mL}$, Peprotech, Rehovot, Israel) for a further 7 days. Following 2 weeks of neural induction, neural progenitors were mechanically harvested and cultured in suspension in neural basal media supplemented with $1 \%$ insulin/transferrin/selenium, $1 \% \mathrm{~N} 2$ supplement, $1 \%$ retinol-free B27 supplement, $0.3 \%$ glucose, $25 \mathrm{U} / \mathrm{mL}$ penicillin, and $25 \mu \mathrm{g} / \mathrm{mL}$ streptomycin, $\mathrm{bFGF},(20 \mathrm{ng} / \mathrm{mL})$ and epidermal growth factor (EGF; $20 \mathrm{ng} / \mathrm{mL}$, Peprotech, Rehovot, Israel) to promote organoid formation [32].

\subsection{Immunoassay Analysis}

Organoids were fixed with $4 \%$ paraformaldehyde and embedded in OCT for cryosectioning. Frozen cryosections were immunostained using rabbit anti-vGlut antibody or mouse anti-GAD67 followed by goat anti-rabbit $(555 \mathrm{~nm})$ or goat anti-mouse $(488 \mathrm{~nm})$ Alexafluor secondary antibodies, respectively. All samples were counterstained with 4',6-diamidino-2-phenylindole (DAPI; $1 \mu \mathrm{g} / \mathrm{mL}$, Sigma-Aldrich, Castle Hill, Australia).

\subsection{HPLC Analysis}

Glutamate analysis was performed using the isocratic HPLC method which utilized naphthalene-2,3-dicarboxylaldehyde (NDA, Sigma-Aldrich, Castle Hill, Australia) derivatisation and subsequent fluorescence detection [33-35]. ESC-derived organoids were lysed by sonication (50\% Amplitude, 3 pulses at $5 \mathrm{~s}$ with $25 \mathrm{~s}$ intervals) in 2\% EDTA, $0.1 \mathrm{M}$ Acetic Acid buffer and then centrifuged at 10,000 rpm for $5 \mathrm{~min}$ at room temperature. Supernatant was collected for HPLC analyses. Fifty $\mu \mathrm{L}$ of either standard solution or sample was added to $450 \mu \mathrm{L}$ of borate buffer $(0.1 \mathrm{M}$, $\mathrm{pH} 9.5), 100 \mu \mathrm{L}$ of $\mathrm{KCN}(10 \mathrm{mM})$ and $100 \mu \mathrm{L}$ of naphthalene-2,3-dicarboxylaldehyde (NDA, $6 \mathrm{mM})$ in a reaction tube, and the derivatization reaction allowed to proceed for $20 \mathrm{~min}$ in the absence of light. The fluorescent glutamate derivative $(25 \mu \mathrm{L})$ was injected into the HPLC system, which consisted of 
a Waters 510 pump, a Bio-Rad AS-100 refrigerated auto sampler and an LDC FluoroMonitor 4100 programmable fluorescence detector at $420 \mathrm{~nm}$ excitation and $480 \mathrm{~nm}$ emission. The column was a $15 \mathrm{~cm} \times 3.9 \mathrm{~mm}$ Waters Novapak $\mathrm{C}_{18}$ column, and the mobile phase was $20 \%$ acetonitrile in $50 \mathrm{mM}$ $\mathrm{KH}_{2} \mathrm{PO}_{4}$ (pH 5.6) running at $2 \mathrm{~mL} / \mathrm{min}$. The method has within-day and between-day coefficients of variation of $1.97 \%$ and $2.94 \%$, respectively, at $1 \mu \mathrm{M}$.

\section{Results and Discussion}

\subsection{Principle of the Amperometric Glutamate Biosensor}

Nanostructured surfaces have excellent prospects for interfacing biological recognition events with electronic signal transduction where active enzymes sites are coupled directly with the nanostructure-based microelectrode resulting in direct electron transfer between the enzyme and signal transducer and thus enhanced biosensing properties. The nanostructured microelectrode provides an electro-active surface for enzyme immobilization with enhanced confirmation, orientation and biological activity.

Electrochemical detection involving the use of an oxidoreductase, i.e., GluOx, typically occurs according to the mechanism depicted in Figure S1. GluOx is one of the key elements when fabricating glutamate sensors for improving selectivity, stability and sensitivity towards glutamate. Glutamate oxidase $(\sim 140 \mathrm{kDa})$ has high substrate specificity to glutamate $\left(\mathrm{k}_{\text {cat }}=75 \mathrm{~s}^{-1}\right.$ and $\left.\mathrm{K}_{\mathrm{m}}=0.23 \mathrm{mM}\right)$ and high stability (thermal stability $\sim 80{ }^{\circ} \mathrm{C}$ ) [36,37]. It converts the substrate, glutamate, in presence of oxygen and water into $\alpha$-ketoglutarate, hydrogen peroxide and ammonia. The hydrogen peroxide produced can be easily detected amperometrically [23]. Following the enzymatic reaction as described

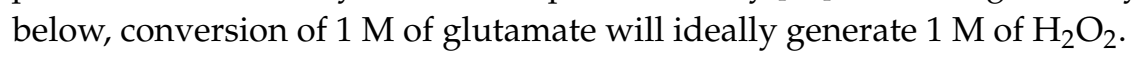

$$
\text { L-glutamic acid }+\mathrm{H}_{2} \mathrm{O}+\mathrm{O}_{2} \stackrel{\mathrm{GluOx}}{\rightarrow} \alpha-\text { ketoglutarate }+\mathrm{NH}_{3}+\mathrm{H}_{2} \mathrm{O}_{2}
$$

The hydrogen peroxide then reacts electrochemically on the Pt electrode as shown below:

$$
\mathrm{H}_{2} \mathrm{O}_{2} \rightarrow 2 \mathrm{H}^{+}+\mathrm{O}_{2}+2 \mathrm{e}^{-}
$$

For an ideal immobilization, the GluOx needs to bind to the electrode firmly and maintain its structure and function properly after immobilization. The most common method for fabricating glutamate biosensors is crosslinking which uses reagent bovine serum albumin (BSA) as the enzyme stabilizer and glutaraldehyde as the crosslinker [21]. BSA is often included in the cross-linked matrix to protect enzyme activity by creating a 3D network for enzyme attachment $[1,38]$. On the other hand, glutaraldehyde is reactive towards the amine groups of lysine residues located mainly on protein surfaces and therefore can crosslink and immobilize GluOx and BSA on the microelectrode surface.

Since other biogenic substances can also be oxidized at the microelectrode probe surface, it was shielded with a permselective membrane to prevent these substances from approaching the signal transducer (platinum layer) [39]. Therefore, prior to surface functionalization, PPD was electropolymerized on the tip of the microelectrode using an amperometric process. The enzymatic layer was then formed by drop-casting a solution comprising BSA, glutaraldehyde and GluOx. The enzymatic layer, GluOx, was immobilized by drop-casting of $10 \mu \mathrm{L}$ of an enzyme solution containing $10 \%$ BSA and $0.125 \%$ glutaraldehyde mixed with $0.5 \mu \mathrm{L}$ GluOx $(1 \mathrm{U} / \mu \mathrm{L})$ on the tip of a borosilicate glass capillary at room temperature and then drying naturally for $\sim 20 \mathrm{~min}$.

\subsection{Glutamate Biosensor Characterisation, Sensitivity and Selectivity Analysis}

To address the analytical applicability of the $\mathrm{Pt} / \mathrm{PDD} / \mathrm{GluOx}$ coated microelectrodes we investigated the electrocatalytic activity of these microelectrodes by measuring the current response at different glutamate concentrations in PBS. Amperometry experiments were conducted using a standard three-electrode set-up with $\mathrm{Ag} / \mathrm{AgCl}$ as the reference and a platinum wire as the counter 
electrode. These experiments were computer controlled with data acquisition that was realized using a CHI760 interface, a low-noise damping potentiostat. The biosensors were initially calibrated as shown in Figure S2a. As described in other publications, electrochemical oxidation of $\mathrm{H}_{2} \mathrm{O}_{2}$ is achieved above $+0.2 \mathrm{~V}$ [40-42]. Therefore, the chronoamperometric responses of the microelectrode were recorded during the successive addition of $5.0 \mu \mathrm{M}$ and $100 \mu \mathrm{M}$ glutamate in $1 \mathrm{M}$ PBS at an applied potential of $+0.7 \mathrm{~V}$ vs. $\mathrm{Ag} / \mathrm{AgCl}$ which is optimal for $\mathrm{H}_{2} \mathrm{O}_{2}$ detection [40]. It was observed that the microelectrode could catalytically detect generated $\mathrm{H}_{2} \mathrm{O}_{2}$ through electrochemical transducer. To quantify the amperometric response, a calibration curve for each biosensor was created linking the current response to the glutamate concentration (Figure S2b). It was found that the biosensors responded linearly $\left(\mathrm{R}^{2}=0.968 \pm 0.007\right)$ to glutamate over the concentration range between $5 \mu \mathrm{M}$ and $0.5 \mathrm{mM}$, with a LOD $(3 \times$ standard measurement error bar of the baseline). Glutamine, of $5.6 \pm 0.2 \mu \mathrm{M}$. indicating suitability for detection of low glutamate levels in many biological applications. Using the linear response range, the sensitivity was determined to be $93 \pm 9.5 \mathrm{nA} \cdot \mu \mathrm{M}^{-1} \cdot \mathrm{cm}^{-2}$ by the slope of the calibration curve for the glutamate biosensor. This is higher than a large number of reported glutamate oxidase based sensors where the sensitivity varies between 2.15 and $65 \mathrm{nA} \cdot \mu \mathrm{M}^{-1} \cdot \mathrm{cm}^{-2}[43,44]$. This can be attributed to the high surface area of the nanostructure-based microelectrode.

Major challenges for enzymatic glutamate detection methods are electrochemically active interferents, which generate electrochemical signals at the same potential as glutamate. Therefore the biosensors were evaluated for interference at an applied potential of $0.7 \mathrm{~V}$ vs. the $\mathrm{Ag} / \mathrm{AgCl}$ in $1 \mathrm{M} \mathrm{PBS}$ solution with continuous additions of $100 \mu \mathrm{M}$ aliquots of dopamine (DA), ascorbic acid (AA), cysteine (Cus), uric acid (UA), serotonin, glucose, dihydroxyphenylacetic acid (DOPAC), alanine (Ala), arginine (Arg), asparagine (Asn), aspartic acid (Asp), glycine (Gly), histidine (His), trans-4-hydroxyl-L-proline (Hyp), isoleucine (Ile), leucine (Leu), lysine (Lys) and glutamate (Glut). It can be observed from the current response in Figure S2c, that only a significant signal was obtained for glutamate compared to the other amino acids. This implies that the $\mathrm{Glu}: \mathrm{H}_{2} \mathrm{O}_{2}$ ratio i.e., the effectiveness of enzyme GluOx to convert glutamate to $\mathrm{H}_{2} \mathrm{O}_{2}$, was not affected by the presence of these potentially interfering substances.

\subsection{Measurement of Glutamate within hESC-Derived Organoids}

We and others have established protocols for generating organoids from hESC that consist of cortical dorsal and ventral neural progenitors, which give rise to glutamatergic and GABAergic neurons, respectively [45-47]. Figure S3 shows glutamatergic and GABAergic neurons by means of an immunostaining method using rabbit anti-vGlut antibody or mouse anti-GAD67 followed by goat anti-rabbit (555 nm) or goat anti-mouse (488 nm) Alexafluor secondary antibodies. Since dorsal and ventral hESC-derived organoids mimic different brain regions with different cell populations, there may also be differences in glutamate levels. To examine this hypothesis, an experimental setup was designed for glutamate measurement inside organoids based on a microelectrode biosensor, Leica M80 stereomicroscope with ESD design and Leica MATS heating system. In this apparatus, shown in Figure $3 a$, the amperometric measurements were carried out in a sterile biohazard fume hood under an upright zoom lens optical microscope. The microelectrode was mounted at an angle of 30-40 degrees from the petri dish and directed into the field of view of the microscope. Then, it was lowered gently and moved toward an organoid using a micromanipulator (SÜSS MicroTec AG, Garching, Germany). The microelectrode was then slid sideways until it pierced an organoid from the side as seen in Figure $3 \mathrm{~b}$ and Figure S5. A potential of $+0.7 \mathrm{~V}$ vs. $\mathrm{Ag} / \mathrm{AgCl}$ was applied to the electrode to record chronoamperograms. The microelectrode stayed still for about $100 \mathrm{~s}$ to allow recording signals in response to glutamate concentration in the organoid before it was retracted. Three independent biosensor readings were taken for each organoid in at least 20 dorsal forebrain organoids and 20 ventral forebrain organoids. 

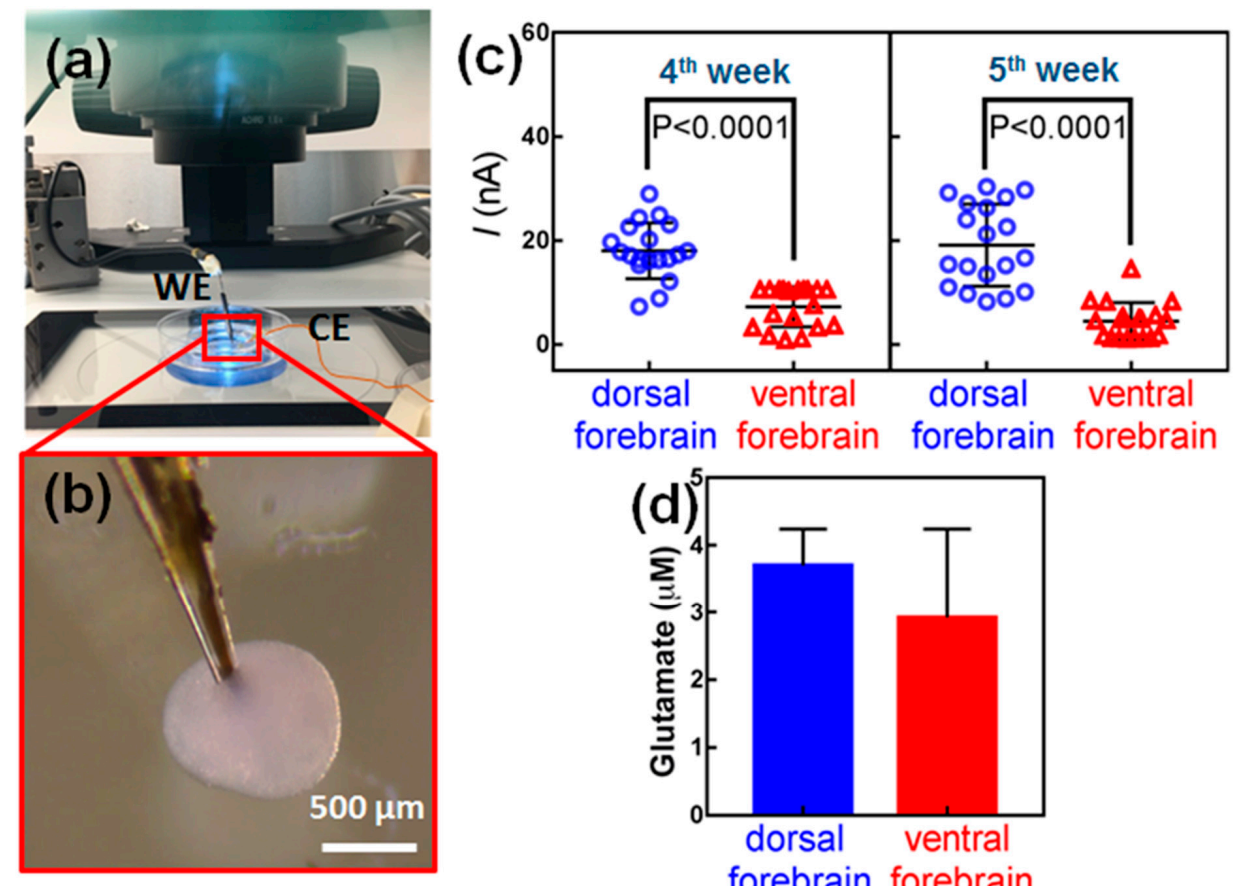

Figure 3. Glutamate measurements in hESC-derived organoids. (a) Image showing the set-up of equipment with dissecting microscope, organoid culture dish and microelectrode on holder attached to a micromanipulator. (b) The microelectrode is first located outside the organoid with an angle of about $40^{\circ}$ against the culture dish. It is then gently forced into the organoid. (c) Biosensor measurements of glutamate levels in dorsal and ventral hESC-derived organoids cultured. Measurements were performed in the same organoids at 4 weeks and 5 weeks in culture. At least 20 organoids were examined for each experiment. $p<0.0001$, Mann-Whitney U test. (d) HPLC analyses of glutamate.

When the microelectrode was inserted in the dorsal forebrain organoid, a strong peak current, in range of $\sim 20 \mathrm{nA}$ to $\sim 30 \mathrm{nA}$ was recorded through data acquisition system, which was attributed to the electrochemical oxidation of glutamate secreted in the organoids and consequent oxidation of $\mathrm{H}_{2} \mathrm{O}_{2}$ (Figure S5). In contrast, a very weak peak current was obtained after insertion of the microelectrode in a ventral forebrain organoid. This clearly revealed that a larger electrochemical response was caused by dorsal forebrain organoids presumably due to higher concentrations of glutamate. The recorded data for every organoid is averaged and presented in Figure 3c. The biosensor readings indicate that dorsal forebrain organoids have significantly higher glutamate levels compared to ventral forebrain organoids at four weeks in culture (Figure $3 c, p<0.0001$ ). The same organoids were measured again at five weeks in culture and consistent results were obtained as shown in Figure 3c. These analyses were further supported by HPLC analyses of lysed organoids, showing higher levels of glutamate in dorsal forebrain relative to ventral (Figure 3d) [48].

\section{Conclusions}

In conclusion, we have developed a novel electrochemical glutamate biosensor for highly sensitive and selective detection of glutamate in stem cells-derived brain organoids. The self-organized nanostructure-textured probe with high surface area provides a higher surface concentration of released electrons at the probe during the electrochemical detection of $\mathrm{H}_{2} \mathrm{O}_{2}$. Under optimal conditions, the detection of glutamate can be achieved with a LOD of $5.6 \pm 0.2 \mu \mathrm{M}$ and sensitivity of $93 \pm 9.5 \mathrm{nA} \cdot \mu \mathrm{M}^{-1} \cdot \mathrm{cm}^{-2}$, which is comparable to reported methods. (Table S1). Overall, these data demonstrate the robustness of the biosensor in detecting glutamate levels within stem cell-derived organoids, and can also be utilized to measure dynamic changes in glutamate levels across time in culture. It is noteworthy that the proposed electrochemical biosensing strategy has the advantages 
of ease of use and low cost. This study provides compelling evidence for the utility of biosensors in developing modelling of human brain function using stem cells.

Supplementary Materials: The following are available online at www.mdpi.com/2079-6374/8/1/14/s1: Figure S1. Bio-detection principle, Figure S2. Electrochemical characterization of a glutamate biosensor, Figure S3. Immunostaining images of hESC-derived cortical organoids, Figure S4. HIM images of hESC-derived cortical organoids, Figure S5. Measurement of glutamate within hESC-derived organoids, Table S1: A comparison of recording characteristics of few microelectrodes for the detection of glutamate.

Acknowledgments: This work was supported by the Australian Research Council Centre of Excellence for Integrative Brain Function (ARC Centre Grant CE140100007). M. Dottori is supported by the Australian Research Council Future Fellowship. The fabrication of glutamate biosensors were partly performed at the Melbourne Centre for Nanofabrication (MCN) in the Victorian Node of the Australian National Fabrication Facility (ANFF). The authors also acknowledge the facilities and technical assistance of the Micro Nano Research Facility (MNRF) at RMIT. The authors acknowledge the opportunity to use the facilities of School of Physics at The University of Melbourne.

Author Contributions: B.N., M.D. and E.S. conceived the use of microelectrodes for detection of glutamate in stem cell derived organoids. B.N., M.D. and E.S. designed the experiments. B.N. and J.H.M.Y. designed and fabricated the biosensors. B.N performed device characterization and bio-detection. R.C., P.J., A.R.B., O.K. and G.M.D. contributed in materials preparation, stem cells derived organoids and analysis tool/data. B.N., A.R.B., G.C. and M.D. wrote the manuscript and reviewed methods and analysed data. All authors discussed the results and commented on the manuscript.

Conflicts of Interest: The authors declare no conflict of interest.

\section{References}

1. Hu, Y.; Mitchell, K.M.; Albahadily, F.N.; Michaelis, E.K.; Wilson, G.S. Direct measurement of glutamate release in the brain using a dual enzyme-based electrochemical sensor. Brain Res. 1994, 659, 117-125. [CrossRef]

2. Camacho, A.; Massieu, L. Role of glutamate transporters in the clearance and release of glutamate during ischemia and its relation to neuronal death. Arch. Med. Res. 2006, 37, 11-18. [CrossRef] [PubMed]

3. Ferrarese, C.; Zoia, C.; Pecora, N.; Piolti, R.; Frigo, M.; Bianchi, G.; Sala, G.; Begni, B.; Riva, R.; Frattola, L. Reduced platelet glutamate uptake in Parkinson's disease. J. Neural Transm. 1999, 106, 685-692. [CrossRef] [PubMed]

4. Niswender, C.M.; Jones, C.K.; Lin, X.; Bubser, M.; Thompson Gray, A.; Blobaum, A.L.; Engers, D.W.; Rodriguez, A.L.; Loch, M.T.; Daniels, J.S.; et al. Development and Antiparkinsonian Activity of VU0418506, a Selective Positive Allosteric Modulator of Metabotropic Glutamate Receptor 4 Homomers without Activity at mGlu2/4 Heteromers. ACS Chem. Neurosci. 2016, 7, 1201-1211. [CrossRef] [PubMed]

5. Hol, E.M.; Roelofs, R.F.; Moraal, E.; Sonnemans, M.A.F.; Sluijs, J.A.; Proper, E.A.; de Graan, P.N.E.; Fischer, D.F.; van Leeuwen, F.W. Neuronal expression of GFAP in patients with Alzheimer pathology and identification of novel GFAP splice forms. Mol. Psychiatry 2003, 8, 786-796. [CrossRef] [PubMed]

6. Walton, H.S.; Dodd, P.R. Glutamate-Glutamine cycling in Alzheimer's disease. Neurochem. Int. 2007, 50, 1052-1066. [CrossRef] [PubMed]

7. Babb, T.L.; Ying, Z.; Hadam, J.; Penrod, C. Glutamate receptor mechanisms in human epileptic dysplastic cortex. Epilepsy Res. 1998, 32, 24-33. [CrossRef]

8. Coulter, D.A.; Eid, T. Astrocytic regulation of glutamate homeostasis in epilepsy. Glia 2012, 60, 1215-1226. [CrossRef] [PubMed]

9. Maragakis, N.J.; Rothstein, J.D. Glutamate transporters: Animal models to neurologic disease. Neurobiol. Dis. 2004, 15, 461-473. [CrossRef] [PubMed]

10. Hires, S.A.; Zhu, Y.; Tsien, R.Y. Optical measurement of synaptic glutamate spillover and reuptake by linker optimized glutamate-sensitive fluorescent reporters. Proc. Natl. Acad. Sci. USA 2008, 105, 4411-4416. [CrossRef] [PubMed]

11. Cordek, J.; Wang, X.; Tan, W. Direct immobilization of glutamate dehydrogenase on optical fiber probes for ultrasensitive glutamate detection. Anal. Chem. 1999, 71, 1529-1533. [CrossRef]

12. Verkhratsky, A.; Parpura, V. History of Electrophysiology and the Patch Clamp; Springer: Berlin, Germany, 2014; Volume 1183, ISBN 9781493910953. 
13. Van der Zeyden, M.; Oldenziel, W.H.; Rea, K.; Cremers, T.I.; Westerink, B.H. Microdialysis of GABA and glutamate: Analysis, interpretation and comparison with microsensors. Pharmacol. Biochem. Behav. 2008, 90, 135-147. [CrossRef] [PubMed]

14. Akagi, Y.; Hashigasako, A.; Degenaar, P.; Iwabuchi, S.; Hasan, Q.; Morita, Y.; Tamiya, E. Enzyme-Linked Sensitive Fluorometric Imaging of Glutamate Release from Cerebral Neurons of Chick Embryos. J. Biochem. 2003, 134, 353-358. [CrossRef] [PubMed]

15. Takano, T.; Kang, J.; Jaiswal, J.K.; Simon, S.M.; Lin, J.H.-C.; Yu, Y.; Li, Y.; Yang, J.; Dienel, G.; Zielke, H.R.; et al. Receptor-mediated glutamate release from volume sensitive channels in astrocytes. Proc. Natl. Acad. Sci. USA 2005, 102, 16466-16471. [CrossRef] [PubMed]

16. Shi, R.; Stein, K. Flow injection methods for determination of L-glutamate using glutamate decarboxylase and glutamate dehydrogenase reactors with spectrophotometric detection. Analyst 1996, 121, 1305-1309. [CrossRef]

17. Khampha, W.; Meevootisom, V.; Wiyakrutta, S. Spectrophotometric enzymatic cycling method using L-glutamate dehydrogenase and D-phenylglycine aminotransferase for determination of L-glutamate in foods. Anal. Chim. Acta 2004, 520, 133-139. [CrossRef]

18. Rakhi, R.B.; Nayuk, P.; Xia, C.; Alshareef, H.N. Novel amperometric glucose biosensor based on MXene nanocomposite. Sci. Rep. 2016, 6, 36422. [CrossRef] [PubMed]

19. Sun, H.; Liu, Z.; Wu, C.; Xu, P.; Wang, X. Amperometric inhibitive biosensor based on horseradish peroxidase-nanoporous gold for sulfide determination. Sci. Rep. 2016, 6, 30905. [CrossRef] [PubMed]

20. Solanki, P.R.; Kaushik, A.; Agrawal, V.V.; Malhotra, B.D. Nanostructured metal oxide-based biosensors. NPG Asia Mater. 2011, 3, 17-24. [CrossRef]

21. Burmeister, J.J.; Davis, V.A.; Quintero, J.E.; Pomerleau, F.; Huettl, P.; Gerhardt, G.A. Glutaraldehyde cross-linked glutamate oxidase coated microelectrode arrays: Selectivity and resting levels of glutamate in the CNS. ACS Chem. Neurosci. 2013, 4, 721-728. [CrossRef] [PubMed]

22. Kergoat, L.; Piro, B.; Simon, D.T.; Pham, M.C.; Noël, V.; Berggren, M. Detection of glutamate and acetylcholine with organic electrochemical transistors based on conducting polymer/platinum nanoparticle composites. Adv. Mater. 2014, 26, 5658-5664. [CrossRef] [PubMed]

23. Sirca, D.; Vardeu, A.; Pinna, M.; Diana, M.; Enrico, P. A robust, state-of-the-art amperometric microbiosensor for glutamate detection. Biosens. Bioelectron. 2014, 61, 526-531. [CrossRef] [PubMed]

24. Abeyrathne, C.D.; Huynh, D.H.; McIntire, T.W.; Nguyen, T.C.; Nasr, B.; Zantomio, D.; Chana, G.; Abbott, I.; Choong, P.; Catton, M.; et al. Lab on a chip sensor for rapid detection and antibiotic resistance determination of Staphylococcus aureus. Analyst 2016, 141, 1922-1929. [CrossRef] [PubMed]

25. Nasr, B.; Chana, G.; Lee, T.T.; Nguyen, T.; Abeyrathne, C.; D’Abaco, G.M.; Dottori, M.; Skafidas, E. Vertical Nanowire Electrode Arrays as Novel Electrochemical Label-Free Immunosensors. Small 2015, 11, 2862-2868. [CrossRef] [PubMed]

26. Lu, D.; Wang, J.; Wang, L.; Du, D.; Timchalk, C.; Barry, R.; Lin, Y. A Novel Nanoparticle-Based Disposable Electrochemical Immunosensor for Diagnosis of Exposure to Toxic Organophosphorus Agents. Adv. Funct. Mater. 2011, 21, 4371-4378. [CrossRef]

27. Stern, E.; Klemic, J.F.; Routenberg, D.A.; Wyrembak, P.N.; Turner-Evans, D.B.; Hamilton, A.D.; LaVan, D.A.; Fahmy, T.M.; Reed, M.A. Label-free immunodetection with CMOS-compatible semiconducting nanowires. Nature 2007, 445, 519-522. [CrossRef] [PubMed]

28. Chikkaveeraiah, B.V.; Bhirde, A.A.; Morgan, N.Y.; Eden, H.S.; Chen, X. Electrochemical immunosensors for detection of cancer protein biomarkers. ACS Nano 2012, 6, 6546-6561. [CrossRef] [PubMed]

29. Lilienthal, K.; Fischer, M.; Stubenrauch, M.; Schober, A. Self-organized nanostructures in silicon and glass for MEMS, MOEMS and BioMEMS. Mater. Sci. Eng. B Solid-State Mater. Adv. Technol. 2010, 169, $78-84$. [CrossRef]

30. Gorton, L. Biosensors and Modern Biospecific Analytical Techniques, 1st ed.; Elsevier Science: Amsterdam, The Netherlands, 2005; Volume 44, ISBN 9780444507150.

31. Denham, M.; Dottori, M. Neural Differentiation of Induced Pluripotent Stem Cells. In Neurodegeneration: Methods and Protocols; Manfredi, G., Kawamata, H., Eds.; Humana Press: Totowa, NJ, USA, 2011; pp. 99-110, ISBN 978-1-61779-328-8.

32. Dottori, M.; Pera, M.F. Neural differentiation of human embryonic stem cells. In Methods in Molecular Biology (Clifton, N.J.); Springer: Berlin, Germany, 2008; Volume 438, pp. 19-30, ISBN 7065830071. 
33. Neal, A.; Yuen, T.; Bjorksten, A.R.; Kwan, P.; O'Brien, T.J.; Morokoff, A. Peritumoural glutamate correlates with post-operative seizures in supratentorial gliomas. J. Neurooncol. 2016, 129, 259-267. [CrossRef] [PubMed]

34. Yuen, T.I.; Morokoff, A.P.; Bjorksten, A.; D'Abaco, G.; Paradiso, L.; Finch, S.; Wong, D.; Reid, C.A.; Powell, K.L.; Drummond, K.J.; et al. Glutamate is associated with a higher risk of seizures in patients with gliomas. Neurology 2012, 79, 883-889. [CrossRef] [PubMed]

35. Liubinas, S.V.; Drummond, K.J.; Desmond, P.M.; Bjorksten, A.; Morokoff, A.P.; Kaye, A.H.; O’Brien, T.J.; Moffat, B.A. Glutamate quantification in patients with supratentorial gliomas using chemical shift imaging. NMR Biomed. 2014, 27, 570-577. [CrossRef] [PubMed]

36. Van Den Heuvel, R.H.H.; Svergun, D.I.; Petoukhov, M.V.; Coda, A.; Curti, B.; Ravasio, S.; Vanoni, M.A.; Mattevi, A. The active conformation of glutamate synthase and its binding to ferredoxin. J. Mol. Biol. 2003, 330, 113-128. [CrossRef]

37. Arima, J.; Sasaki, C.; Sakaguchi, C.; Mizuno, H.; Tamura, T.; Kashima, A.; Kusakabe, H.; Sugio, S.; Inagaki, K. Structural characterization of L-glutamate oxidase from Streptomyces sp. X-119-6. FEBS J. 2009, 276, 4318-4327. [CrossRef] [PubMed]

38. Burmeister, J.J.; Gerhardt, G.A. Self-referencing ceramic-based multisite microelectrodes for the detection and elimination of interferences from the measurement of L-glutamate and other analytes. Anal. Chem. 2001, 73, 1037-1042. [CrossRef] [PubMed]

39. Geise, R.J.; Adams, J.M.; Barone, N.J.; Yacynych, A.M. Electropolymerized films to prevent interferences and electrode fouling in biosensors. Biosens. Bioelectron. 1991, 6, 151-160. [CrossRef]

40. Wahono, N.; Qin, S.; Oomen, P.; Cremers, T.I.F.; de Vries, M.G.; Westerink, B.H.C. Evaluation of permselective membranes for optimization of intracerebral amperometric glutamate biosensors. Biosens. Bioelectron. 2012, 33, 260-266. [CrossRef] [PubMed]

41. Hall, S.; Khudaish, E.; Hart, A. Electrochemical oxidation of hydrogen peroxide at platinum electrodes. Part II: Effect of potential. Electrochim. Acta 1998, 43, 2015-2024. [CrossRef]

42. Cai, L.T.; Chen, H.Y. Electrocatalytic reduction of hydrogen peroxide at platinum microparticles dispersed in a poly(o-phenylenediamine) film. Sens. Actuators B Chem. 1999, 55, 14-18. [CrossRef]

43. McMahon, C.P.; Rocchitta, G.; Serra, P.A.; Kirwan, S.M.; Lowry, J.P.; O'Neill, R.D. The efficiency of immobilised glutamate oxidase decreases with surface enzyme loading: An electrostatic effect, and reversal by a polycation significantly enhances biosensor sensitivity. Analyst 2006, 131, 68-72. [CrossRef] [PubMed]

44. Weltin, A.; Kieninger, J.; Enderle, B.; Gellner, A.K.; Fritsch, B.; Urban, G.A. Polymer-based, flexible glutamate and lactate microsensors for in vivo applications. Biosens. Bioelectron. 2014, 61, 192-199. [CrossRef] [PubMed]

45. Alshawaf, A.J.; Antonic, A.; Skafidas, E.; Ng, D.C.H.; Dottori, M. WDR62 Regulates Early Neural and Glial Progenitor Specification of Human Pluripotent Stem Cells. Stem Cells Int. 2017, 2017. [CrossRef] [PubMed]

46. Birey, F.; Andersen, J.; Makinson, C.D.; Islam, S.; Wei, W.; Huber, N.; Fan, H.C.; Metzler, K.R.C.; Panagiotakos, G.; Thom, N.; et al. Assembly of functionally integrated human forebrain spheroids. Nature 2017, 545, 54-59. [CrossRef] [PubMed]

47. Chambers, S.M.; Fasano, C.A.; Papapetrou, E.P.; Tomishima, M.; Sadelain, M.; Studer, L. Highly efficient neural conversion of human ES and iPS cells by dual inhibition of SMAD signaling. Nat. Biotechnol. 2009, 27, 275-280. [CrossRef] [PubMed]

48. Clarke, G.; O'Mahony, S.; Malone, G.; Dinan, T.G. An isocratic high performance liquid chromatography method for the determination of GABA and glutamate in discrete regions of the rodent brain. J. Neurosci. Methods 2007, 160, 223-230. [CrossRef] [PubMed]

(C) 2018 by the authors. Licensee MDPI, Basel, Switzerland. This article is an open access article distributed under the terms and conditions of the Creative Commons Attribution (CC BY) license (http://creativecommons.org/licenses/by/4.0/). 